\title{
Cosmetic injectables under MPs' spotlight
}

The British Dental Association (BDA) has urged dentists to be appropriately protected, as MPs call on the government to end the 'Wild West' of non-surgical beauty treatments.

Many patients seeking cosmetic treatment remain unaware of the degree of protection that is missing when seeking apparently similar treatment from an unregulated individual working from premises that have not been inspected by the CQC. The All-Party Parliamentary Group on Beauty, Aesthetics and Wellbeing is calling on the government to address the need for regulation of such procedures and the associated injectable cosmetic agents, including appropriate insurance.

MPs spent a year on an inquiry and have made 17 recommendations following concerns that currently anyone can carry out any treatment, with minimal legal restrictions on who can provide them or

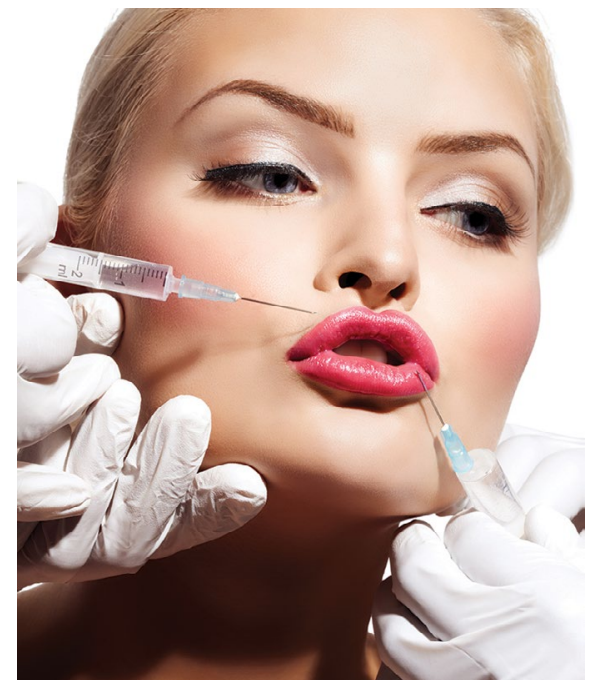

what qualifications they must have to do so. ${ }^{1}$ The insufficient legal framework governing these treatments has left patients at risk and undermined the industry's ability to develop. Len D'Cruz, Head of BDA Indemnity, said: 'Our policyholders are indemnified for the use and administration of facial cosmetic injectable procedures above the lower border of the mandible. This is part of all Extra and Expert members' policy terms. This has been the case since the indemnity policy exclusively for BDA members was launched three years ago.

'The use of injectable cosmetic treatments in the peri-oral area is a useful adjunct to dental treatment when provided by a suitably trained dentist. In addition, your patients are protected by your indemnity arrangements and a process for managing complaints if anything should go wrong.

'The GDC considers these treatments within the scope of practice of dentists providing appropriate training has been undertaken.'

\section{Reference}

1. APPG Beauty, Aesthetics \& Wellbeing. Inquiry into Aesthetic Non-Surgical Cosmetic Treatments. 2020. Available at: https://baw-appg.com/inquiry-nonsurgical-cosmetic-procedures/ (accessed August 2021). 